\title{
PROGRESSIVE MUSCULAR ATROPHY
}

\author{
ACCOMPANIRD BY \\ MUSCULAR RIGIDITY AND CONTRACTION OF \\ JOINTS.
}

EXAMINATION OF THE BRAIN AND SPINAL CORD.

BY

J. LOCKHART CLARKE, M.D., F.R.S.

COMMUNICATED BY

Sir WILLIAM GULL, BART., M.D., F.R.S.

(Reccived October 29th-Read November 12th, 1872.)

The following clinical history of the case was communicated to me by Mr. Stephen Mackenzie of the London Hospital.

"Henry W-, æt. 60, was admitted into the London Hospital under the care of Dr. Ramskill. His family history was good; he was one of thirteen children, all of whom lived to a good old age, with the exception of those who died of fevers and acute diseases. He worked in a velvet manufactory, and the part of the process in which he was employed involved the use of a machine which caused a succession of knocks to his epigastrium, which often made him feel faint, and produced, he believed, continued indigestion. This employment he followed for forty years.

Up to the age of thirty he enjoyed good health, but at 
this time he was seized with vertigo, for which he attended this and St. Bartholomew's Hospital and which continued, on and off, for three years. From this time he found that he was obliged to be very slow in all his movements, and that if he attempted to move his arms and legs quickly, they trembled very much.

In May, 1869, he observed that his legs gave way under him, sometimes, when he walked. Without feeling in any way giddy, he would sometimes fall down, but picked himself up and went on again. He thought the left leg was the first to be affected, and first noticed wasting in the calf of this leg. Then the right leg wasted, and four months later he noticed wasting of the left shoulder. When asked if he had pain at this time, he said he had pain in the loins, but laid great stress upon a severe dragging pain in the arms and legs, which he likened to " his veins being dragged out" or to, "strings drawing up his arms" especially increased on movement.

On admission he was unable to stand, or to turn or move himself in bed, so that he lay in one position until shifted by the nurse. He was quite incapable of feeding himself or, indeed, of moving his arms. He was able to move his fingers just a little. His forearms were kept constantly flexed on his arms, his hands on his forearms with fingers contracted, and the knees slightly drawn up.

The whole of his muscles from the head downwards were much wasted, especially those of the upper extremities, with the pectorals and deltoids. The interossei and muscles of the thumbs were not disproportionately affected.

A fibrillar tremor was seen running more or less constantly down the arms and legs. All his muscles were very rigid and this rigidity could not be overcome. When attempts were made to move his arms and legs, great pain was caused, which he always compared to "the veins being dragged out."

The respiratory movements were very feeble. He had no facial paralysis and said that he had not had any trouble with his bladder. There was no alteration of cutaneous 
sensibility, but electric sensibility was greatly diminished, almost annulled.

His speech was peculiar, being indistinct and interrupted by pauses, with a slight nasal twang. He was a cheerful good tempered old man, and eat well, but slept badly.

The atrophy of muscles increased slowly at first, but rapidly at last. When he came into the hospital he was sat propped up in a chair part of the day, but about November this fatigued him so much that it was discontinued.

His respiratory movements became more and more feeble, swallowing became difficult, and at last almost impossible. The nasal character of his speech, but little noticed on admission, became more and more marked, and at last he became wholly unintelligible. Saliva ran from his mouth and, he said, the tears from his eyes. In this miserable condition he lingered for some weeks, and died on December 18th, 1871.

There are two points of great interest not noticed above. The fibrillar tremor which was so marked on admission, disappeared about the end of September, and the rigidity which was such a prominent feature of the case from the very beginning, wholly disappeared during the last week of his life."

The parts which I received for examination consisted of a slice of one of the cerebral hemispheres, the cerebellum, pons Varolii, medulla oblongata, and spinal cord.*

On examining sections of the cerebral convolutions, the white substance was found to be rather thickly interspersed with corpora amylacea varying from about twice the diameter of a blood disc to fourteen times that size. In the gray substance only a few of these bodies were present, and they were confined chiefly to the deeper layers. Many of the blood.

* On inquiring of Mr. Stephen Mackenzie whether the brain and semilunar ganglion had been examined at the autopsy, I was informed that in the brain there were no naked-eye appearances of disease beyond slight wasting of the convolutions. The brain substance was rather firmer than natural; the solar plexus and semilunar ganglion were not examined. On examination under the microscope nothing abnormal was observed in the voluntary muscles. 
vessels of the white substance were enlarged, but with almost an entire absence of the granules of hæmatoidin, which I have generally found so abundant in the perivascular sheaths of the dilated vessels in general paralysis and some other cerebral diseases.

The cells of the grey substance were not altogether healthy. Some of them had lost their natural sharpness of outline, others contained rather more pigment than usual, or were somewhat granular at their surfaces.

The pons Varolii was below the average size, but presented nothing unusual in external appearance. In transverse sections, however, examined under the microscope, it was readily seen that many of the blood-vessels were much dilated. In some instances they had undergone partial disintegration at particular points, and in others they had wholly disappeared, leaving large empty and smooth-walled tubular spaces, which, according as they were cut transversely or obliquely, presented the appearance of round or oval vacuities, such as I first described in a case of general paralysis of the insane.* At nearly all parts of the sections, and particularly in the white portions, corpora amylacea were rather thickly but uniformly scattered. Moreover, the cells of the common nucleus of the abducens and facial nerves, of the motor nucleus of the trigeminus, as well as those scattered amongst the arciform fibres and plexus of the pons, had undergone more or less pigmentary degeneration.

The medulla oblongata was about one fifth below the average adult size. The hypoglossal, spinal accessory and vagus nuclei were notably smaller than usual. Like the pons, the medulla oblongata was interspersed throughout with corpora amylacea of different sizes, and the groups of cells constituting the several nuclei were more or less affected by pigmentary degeneration. Those of the gray tubercle of Rolando (caput cornu posterioris), and those especially of the restiform body suffered most. The latter under a low magnifying-power had the appearance of a chocolate-coloured mass, but under a higher power it was

* 'Journal of Mental Science,' January, 1870. 
seen that while many of the cells were completely filled with brown pigment, in others the pigment granules only enveloped their nuclei, or accumulated at one side of the cell, or formed a brown ring of variable breadth at the circumference. This morbid change constitutes in many instances, as I have elsewhere shown, the first stage in the degeneration and subsequent disintegration of nerve cells.*

The diameter of the spinal cord was at least one fourth smaller than the average size in the adult. When it was sent to me without any explanation, I thought it was the spinal cord of a child about fourteen years of age ; but there was nothing else abnormal in external appearance. Nevertheless, the grey substance from one end to the other, was severely damaged by a variety of lesions and degenerations. In the upper cervical region on a level with the second and third pairs of nerves, all the white columns were much congested; the connective tissue between their fibres was greatly hypertrophied, with proliferation of the connective tissue corpuscles which were aggregated in small groups of different sizes at the angles of junction in the network, as represented in the posterior column $P$, Plate I, fig. 1 , on the left side. This condition was still more marked in the posterior portions of the antero-lateral columns (L) in which many of the nerve-fibres had suffered from disintegration. In the left lateral half of the grey substance a large triangular and somewhat transparent area of distintegration (D) was found in the interior of the anterior cornu, leaving only a wall of healthy and darker tissue around it. This morbid area consisted only of small remnants of partially disintegrated grey substance, irregularly connected with each other, and forming together a kind of reticular or honeycomb structure. On the right side a large area of transparent disintegration involved the whole outer half of the anterior cornu, (D) and reached as far back as the projecting group of cells, $(t, i, l$,$) which I named the tractus inter-$

* Beale's 'Archives of Medicine,' No. xiii, vol. iv, 1863, “A Case of Rapid Wasting-palsy from Disease of the Spinal Cord,” p. 41, plate vi, fig. 30. 
medio-lateralis, and showed to be connected with the lower rootlets of the spinal accessory nerve.* At the base of the anterior cornu and the lateral boundary of the pyriform posterior vesicular column $(p, v c)$, was a comparatively large and fusiform hæmorrhagic clot, the outer end of which extended into the tractus intermedio-lateralis. Immediately behind this was a larger pyramidal clot; and still further back, at the inner angle of the caput cornu posterioris, and involving part of the gelatinous substance $(g)$, was a smaller clot connected with a blood-vessel which extended into the posterior column.

A little lower down in the cervical region (Plate I, fig. 2), the right lateral half of the grey substance was displaced or depressed towards the corresponding side. The tractus intermedio-lateralis $(t, i, l)$, a large portion of the cervix cornu posterioris $(d)$, and the outer half of the anterior cornu were destroyed by disintegration. In the left lateral half of the grey substance, the same kind of lesion occupied nearly the corresponding parts, but in a less advanced state.

The cervical enlargement of the cord was so much atrophied that its diameter scarcely exceeded that of the portion above it. Yet the areas of disintegration were not so extensive; they were smaller and more irregular, but mostly in the corresponding localities.

In the dorsal region of the cord, (Plate I, fig. 3), both the grey and white substances were much congested, and many of the blood-vessels were dilated ; but the areas of disintegration were less, and confined chiefly to the lateral border of the grey substance, involving the tractus intermedio-lateralis.

The diameter of the lumbar enlargement was not much below the average, nor did its external appearance indicate the existence of disease; yet the grey substance here was quite as severely damaged as in the cervical region. In (Plate I, fig. 4), on the left side, a large and increasing area of softening and distintegration is seen to extend from the outer side, $d$, of the base of the caput cornu posterioris to the 
middle of the anterior cornu ; and on the right side, from the corresponding point to the lateral part of the anterior cornu. In these areas partially disintegrated masses of the grey substance are more or less separated from each other by lighter spaces in which the disintegration is further advanced; so that the structure presents a somewhat mottled appearance.

In all regions of the cord the nerve cells of different parts, but particularly of the anterior grey substance, had undergone considerable degeneration and disintegration. Some were completely, others only partially, filled with darkbrown pigment granules, which in many instances enveloped and concealed their nuclei. Sometimes the pigment granules were irregularly grouped within the cells, as at $a$ fig. 5; or they accumulated at one end, or at both ends of an elongated cell, as at $b$; and sometimes they formed a partial or entire ring of variable depth within the circumference of the cell, leaving a transparent portion in the centre, as at $e$. All the remaining cells were considerably reduced in size, and their processes were much shrunk, as may be seen by comparison with cells from the corresponding part of a healthy cord (Plate I, fig. 6). Many of them seemed to have been lost by gradual atrophy; but it was evident that numbers had disappeared by complete disintegration. This process of destruction could be traced through all its stages. In some places a cell could be seen actually falling into a heap of granules, as at $f, f$; while in others the granules into which it had been disintegrated were more or less dispersed and irregularly scattered between the still-existing but wasted cells, as at $h, h$.

Remarks.-The symptoms of this case are very clearly explained by the morbid changes that were found in the medulla oblongata and spinal cord. The embarrassed articulation, the nasal character of the voice, the difficulty in swallowing, and the constant escape of saliva from the mouth resemble the group of symptoms which constitutes glossolabio-laryngeal paralysis, and are explained by the morbid 
changes found in the nuclei of the facial, hypoglossal, vagus, and spinal accessory nerves. The great feebleness of the respiratory movements is accounted for by the lesions that were found in the anterior and lateral grey substance of the cervical and dorsal regions of the cord, including the tractus intermedio lateralis, $(t, i, l$, ) which I formerly showed to be connected with lower rootlets of the spinal-accessory nerve, and with the anterior spinal roots supplying the respiratory muscles. The same progressive lesion of the anterior grey substance in the dorsal and lumbar regions of course explains the paralysis of the upper and lower extremities. According to Dr. Charcot, the contraction and stiffness of the joints in similar cases are due to sclerosis of the posterior portion of the antero-lateral columns.* There certainly was in this case, as I have already stated, decided sclerosis of that portion of the antero-lateral columns.

* 'Archives de Physiologie Normale et Pathologique,' 1869. 


\section{DESCRIPTION OF PLATE 1.}

Fig. 1.-Transverse section of the spinal cord between the second and third cervical nerves. $\Delta$, Anterior column; L, posterior portion of lateral column; P, posterior column, showing hypertrophy of its connective tissue; $g$, the gelatinous substance; $p, v, c$, the posterior vesicular column; $t, i, l$, the tractus intermedio-lateralis; $d, d$, the anterior cornu of grey substance, in a state of softening and disintegration. Behind $d$ on the right side are three comparatively large hæmorrhagic clots.

Fig. 2.-Transverse section of the grey substance of the cord a little lower down in the cervical region. The same letters indicate the corresponding parts.

Fig. 3.-Transverse section of the grey substance in the dorsal region of the cord.

Fig. 4.-Transverse section of the grey substance of the lumbar enlargement of the cord. $d$, Outer side of the base of the caput cornu posterioris. On the right side a dilated blood-vessel is seen in the middle of the softened and partially disintegrated anterior cornu.

Fig. 5.-Nerve-cells from the anterior cornu of the lumbar enlargement in variable states of degeneration and disintegration. Some are completely, others only partially, filled with brown pigment. They are all considerably shrunk, and their processes are much wasted, as may be seen on comparison with Fig. 6.

Fig. 6 represents nerve-cells from a corresponding part in a normal state, and magnified to the same extent. Some have disappeared by falling into a heap of particles as at $f, f$; in other places these particles have become scattered between the still-existing cells, as at $h, h$. 


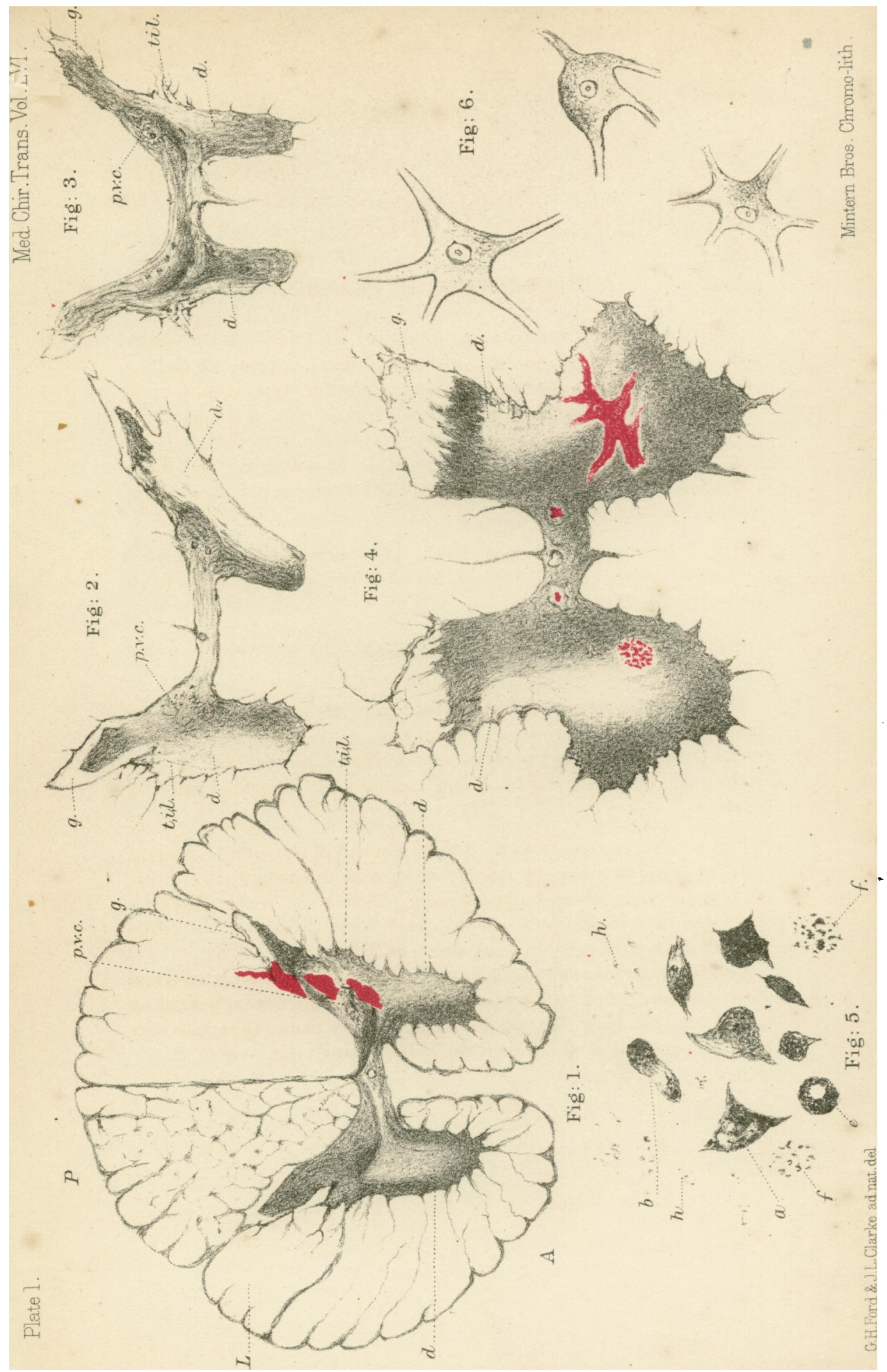

